See discussions, stats, and author profiles for this publication at: https://www.researchgate.net/publication/317845213

\title{
Temperature-time dependent transmittance, sheet resistance and bonding energy of reduced graphene oxide on soda lime glass
}

Article in Applied Surface Science · June 2017

Dol: 10.1016/j.apsusc.2017.06.224

CITATIONS

2

6 authors, including:

Raj Kumar

Indian Institute of Technology Roorkee

4 PUBLICATIONS 9 CITATIONS

SEE PROFILE

(2) Ariharan S.

Indian Institute of Technology Kanpur

20 PUBLICATIONS 171 CITATIONS

SEE PROFILE
READS

452

Manoj Kumar Rangswamy

Indian Institute of Technology Roorkee

15 PUBLICATIONS 148 CITATIONS

SEE PROFILE

Indranil Lahiri

Indian Institute of Technology Roorkee

59 PUBLICATIONS 1,746 CITATIONS

SEE PROFILE

Some of the authors of this publication are also working on these related projects:

Project Synthesis and Applications of Boron Nitride Nanostructures View project

Oxidation and Protection of Graphite for Nuclear Reactor Sponsored by, Board of Nuclear Research). View project 
Full Length Article

\title{
Temperature-time dependent transmittance, sheet resistance and bonding energy of reduced graphene oxide on soda lime glass
}

\author{
Raj Kumar ${ }^{\mathrm{a}}$, R. Manoj Kumar ${ }^{\mathrm{b}}$, Parthasarathi Bera ${ }^{\mathrm{c}}$, S. Ariharan ${ }^{\mathrm{d}}$, Debrupa Lahiri ${ }^{\mathrm{b}, \mathrm{e}}$, \\ Indranil Lahiri ${ }^{\mathrm{a}, \mathrm{e}, *}$ \\ a Nanomaterials and Applications Lab., Department of Metallurgical and Materials Engineering, Indian Institute of Technology Roorkee, Roorkee 247667, \\ India \\ ${ }^{\mathrm{b}}$ Biomaterials and Multiscale Mechanics Lab., Department of Metallurgical and Materials Engineering, Indian Institute of Technology Roorkee, Roorkee \\ 247667, India \\ ' Surface Engineering Division, CSIR-National Aerospace Laboratories, Bengaluru 560017, India \\ ${ }^{\mathrm{d}}$ Department of Materials Science and Engineering, Indian Institute of Technology Kanpur, Kanpur 208016, India \\ e Centre of Excellence: Nanotechnology, Indian Institute of Technology Roorkee, Roorkee 247667, India
}

\section{A R T I C L E I N F O}

\section{Article history:}

Received 9 March 2017

Received in revised form 21 June 2017

Accepted 21 June 2017

Available online 23 June 2017

\section{Keywords:}

Transparent

Conducting coating

Delamination energy

Nano-scratch

\begin{abstract}
A B S T R A C T
Reduced graphene oxide coated soda lime glass can act as an alternative transparent/conducting electrode for many opto-electronic applications. However, bonding between the deposited reduced graphene oxide film and the glass substrate is important for achieving better stability of the coating and an extended device lifetime. In the present study, delamination energy of reduced graphene oxide on soda lime glass was quantified by using nanoscratch technique. Graphene oxide was deposited on soda lime glass by dip coating technique and was thermally reduced at different temperatures $\left(100^{\circ} \mathrm{C}, 200^{\circ} \mathrm{C}, 300^{\circ} \mathrm{C}, 400{ }^{\circ} \mathrm{C}\right.$ and $500{ }^{\circ} \mathrm{C}$ ) and treatment time $(2 \mathrm{~h}, 3 \mathrm{~h}, 4 \mathrm{~h}, 5 \mathrm{~h}$ and $10 \mathrm{~h})$ in $\mathrm{Ar}(95 \%)$ with $\mathrm{H}_{2}(5 \%)$ atmosphere. An inverse behavior of delamination energy with temperature and treatment time was observed, which could be correlated with the removal of oxygen functional groups. Sheet resistance of the film demonstrated a steady decay with increasing temperature and treatment time. Functional groups attached to the graphene planes have more influence on conductivity than groups attached to the edges. Removal of functional groups could also be related to optical transmittance of the samples. Knowledge generated in this study with respect to delamination energy, sheet resistance and optical transmittance could be extensively used for various opto-electronic applications.
\end{abstract}

(C) 2017 Elsevier B.V. All rights reserved.

\section{Introduction}

Two-dimensional (2D) materials like graphene have found great attention in a myriad of device applications. With high conductivity, strength, transparency and catalytic behavior, graphene stands in the list of most-sought materials used in sensors, energy conversion and storage, electronic displays etc. [1]. Hexagonally arrayed, $\mathrm{sp}^{2}$ hybridized graphene is the thinnest material (a single atomic dimension layer) with high carrier mobility, excellent optical transparency, good thermal conductivity, high Young's modulus and large specific area. Due to high conductivity and large specific area, graphene has low charge transfer resistance [2].

* Corresponding author at: Nanomaterials and Applications Lab., Department of Metallurgical and Materials Engineering, Indian Institute of Technology Roorkee, Roorkee 247667, India.

E-mail addresses: indrafmt@iitr.ac.in, indranil.lahiri@gmail.com (I. Lahiri).
Graphene can be synthesized by various methods including mechanical exfoliation, epitaxial growth, chemical vapor deposition and graphene oxide reduction. While the first three processes yield relatively perfect structure and better electronic properties, the last technique is popular as a low cost and high yield method, producing less perfect structure of graphene. Graphene oxide (GO) forms stable aqueous colloidal suspension, owing to its hydrophilic property. Reduction of graphene oxide by different method partly restores graphene structure and property. Properties of reduced graphene oxide ( $\mathrm{rGO}$ ) strongly depend on the efficiency of the reduction methods, directly influencing performance of the device in which rGO is used [3].

One of the ways to reduce GO is to thermally reduce graphene oxide under reducing and/or inert gas atmosphere. Thermal reduction can be performed in two ways: 1) rapid heating and 2) slow heating. During rapid heating, oxygen containing functional groups create high pressure between the layers by decomposing of $\mathrm{CO}$ 
and $\mathrm{CO}_{2}$ gases and their sudden expansion causes mechanical exfoliation of the structure. The dual effects of thermal reduction, exfoliation and reduction, make it a good method to produce graphene in bulk quantity. However, structural defect and small size are the main problem of rapid heating. During rapid heating, decomposed functional groups also remove carbon atoms from the structure due to the high energy provided by decomposition carbon dioxide, which creates distortion in the carbon planes, leading to breakage of graphene sheets into smaller sizes. Thus, rapid heating provides small sized, wrinkled and structurally damaged graphene sheet. On the other hand, slow heating during reduction helps graphene to retain its structure by preventing rapid expansion of the sheets. However, slow heating is a time consuming process [3].

Studies have shown that reduction of graphene oxide can be performed at high temperature [4-6]. But, if the rGO film is to be used on low melting substrates, e.g. glass and polymers, then in-situ reduction at high temperature becomes difficult. Thus, graphene oxide can be reduced in a reducing atmosphere with or without inert gas. Hydrogen has high reducing ability at lower temperature due to which graphene oxide can be reduced at low temperature in hydrogen atmosphere [3].

Apart from the reduction of the GO film, bonding between the film and the substrate is another important factor which decides life of a device. A loosely bonded film will be peeled-off easily leading to damage of the device. Quantification of the delaminating energy of thin films with substrates creates interest for understanding the bonding mechanism which can be linked to the thin film deposition process and the reduction mechanism. Delamination energy can be measured popularly by two methods: 1) Double Cantilever Beam (DCB) method and 2) Nano Scratch technique. Among these two methods, DCB has few limitations [7]. DCB is generally applicable to the 3-D micro/macro materials; not to 2-D thin materials. Further, DCB provides insufficient information about homogeneity of the delamination energy throughout the substrate. On the other hand, nano scratch technique can be applied on 1-D materials (carbon nanotube), 2-D materials (graphene) and a single biological cell [8] also. This sophisticated technique is very consistent and straightforward with presumption during calculation. In this technique, delamination energy of the film with substrate is measured by using a nano-indenter. A lateral force is applied through the interface of the film and the substrate and delaminating energy was measured by calculating the area of the lateral force-lateral displacement curve $[9,10]$.

In the present study, GO film on soda lime glass was reduced at different temperature and treatment time combinations and their optical transmittance, electrical resistance and adhesion energy was quantified to understand the effectiveness of the reduction process. Previous study [11] showed that graphene film could be peeled-off easily from fluorine doped tin oxide (FTO) substrate, if reduced above $400^{\circ} \mathrm{C}$, due to burning out of the organic binder (e.g. terpineol and cellulose). However, no quantification was performed in this perspective. Annealing temperature and treatment time play important roles in the quality of the deposited film. There were a number of studies, on deposition/reduction of graphene oxide on different substrate using different methods; but no quantitative study on predicting the quality of the film was performed. In one of our previous studies [12], rGO based transparent conducting electrode was prepared and de-bonding energy of rGO film with soda lime glass was measured for one processing parameter. However, it was felt that the exciting properties of rGO based transparent conducting electrodes (TCEs), i.e., resistance, transmittance and de-bonding energy, could well be related to the processing conditions. Thus, in this study, nanoscratch technique was used to understand the adhesion of graphene oxide film on soda lime glass at different temperature and treatment time conditions; for optimizing adhesion of the film with substrate for better life of the device. Simultaneously, resistance and transmittance of the films were also characterized in order to generate a comprehensive idea about the TCE application of rGO films on soda lime glass. To the best of our knowledge, this is the first study to quantify the delamination energy, resistance and transmittance of reduced graphene oxide film, reduced at different temperature and treatment time combinations, deposited on soda lime glass.

\section{Materials and methods}

Graphite powder (average particle size $\sim 100 \mu \mathrm{m}$ ) was purchased from S D Fine Chem Limited. Potassium permanganate $\left(\mathrm{KMnO}_{4}, 99 \%\right)$, sulfuric acid $\left(\mathrm{H}_{2} \mathrm{SO}_{4}, 98 \%\right)$, phosphoric acid $\left(\mathrm{H}_{3} \mathrm{PO}_{4}\right.$, $88 \%)$, hydrogen chloride $(\mathrm{HCl}, 35.4 \%)$ and hydrogen peroxide $\left(\mathrm{H}_{2} \mathrm{O}_{2}\right.$, $30 \%$ ) were purchased from Rankem. All the chemicals were of analytical reagent grade. Soda lime glass slides (thickness $1.1 \mathrm{~mm}$ ) were purchased from AICIL LAB (I) Pvt. Ltd. (India).

Graphene oxide was synthesized by modified Hummer's method [12-14]. GO was deposited on soda lime glass with concentration of $1.25 \mathrm{mg} / \mathrm{ml}$ by dip coating method with 10 times dip cycles (thickness $\sim 260 \mathrm{~nm}$ ). After deposition, samples were put in a controlled atmosphere furnace for thermal reduction at $100^{\circ} \mathrm{C}$, $200^{\circ} \mathrm{C}, 300^{\circ} \mathrm{C}, 400^{\circ} \mathrm{C}$ and $500^{\circ} \mathrm{C}$ with heating rate of $5^{\circ} \mathrm{C} / \mathrm{min}$. Further, reduction was performed for selected samples for $2 \mathrm{~h}, 3 \mathrm{~h}, 4 \mathrm{~h}$, $5 \mathrm{~h}$ and $10 \mathrm{~h}$ at $200^{\circ} \mathrm{C}$, in $\mathrm{Ar}+\mathrm{H}_{2}(95 \%+5 \%)$ atmosphere. Cooling was done in $\mathrm{Ar}$ atmosphere only.

$\mathrm{X}$-ray diffraction patterns were taken in thin film X-ray diffractometer (D8 Advance, Bruker, Germany) with $\mathrm{Cu} \mathrm{K} \alpha$ radiation (of wavelength $1.5405 \AA$ ). XRD, having Ni filter, was operated at $40 \mathrm{kV}$ and $30 \mathrm{~mA}$. XRD patterns were recorded in the range of $5-50^{\circ}$ with a scan rate of $1 \% \mathrm{~min}$. Hitachi UH5300 UV-vis-NIR Spectrometer was used to study the transmittance of the films in visible range (380-700 $\mathrm{nm})$. TEM images and SAED patterns were taken from transmission electron microscope (model: FEI TECHNAI G2). Sheet resistance was measured by two point probe method with Keithley 4200 Semiconductor Characterization System. Hysitron Triboindentor TI950 (Hysitron Inc., Minneapolis, USA) was used to study the delamination energy of the film with the substrate, by using a Berkovich diamond tip with radius of $\sim 100 \mathrm{~nm}$. $20 \mu \mathrm{m}$ long scratches were made by the tip at a speed of $0.5 \mu \mathrm{m} / \mathrm{s}$ and $10 \mu \mathrm{N}$ normal force.

X-ray photoelectron spectroscopy (XPS) of GO and heat-treated rGO samples were recorded with a Thermo Scientific Multilab 2000 spectrometer using non-monochromatic AlK $\alpha$ radiation $(1486.6 \mathrm{eV})$ at $15 \mathrm{kV}$ and $10 \mathrm{~mA}$ as X-ray source. The binding energies reported here were calculated with reference to $C 1 \mathrm{~s}$ peak at $284.6 \mathrm{eV}$. For XPS analysis, samples were mounted on the sample holders and were placed into a load-lock chamber with an ultrahigh vacuum (UHV) of $8 \times 10^{-8}$ mbar for $5 \mathrm{~h}$ in order to desorb any volatile species present on the surface. After $5 \mathrm{~h}$, samples were transferred into the analyzing chamber with UHV of $5 \times 10^{-10} \mathrm{mbar}$ one by one. All the spectra were obtained here in the digital mode on a computer with $25 \mathrm{eV}$ pass energy across the hemispheres of the electron analyzer and $0.05 \mathrm{eV}$ step increment.

\section{Results and discussion}

Reduction of graphene oxide was confirmed by XRD (Fig. 1(a)). The single prominent peak of $\mathrm{GO}(002)$ at $10.14^{\circ}$ with $\mathrm{d}$-spacing of $8.71 \AA$ was observed to be absent at different reduction temperatures. The peaks of thermally reduced graphene oxide at different temperatures of $100-500^{\circ} \mathrm{C}$ were observed between $24.17^{\circ}-24.57^{\circ}$ with d-spacing in the range of $3.67 \AA-3.61 \AA$. This reduction in dspacing (from $8.71 \AA ̊$ in GO to $3.61 \AA \AA$ in rGO) was occurred due to the removal of oxygen functional groups as well as water molecules 

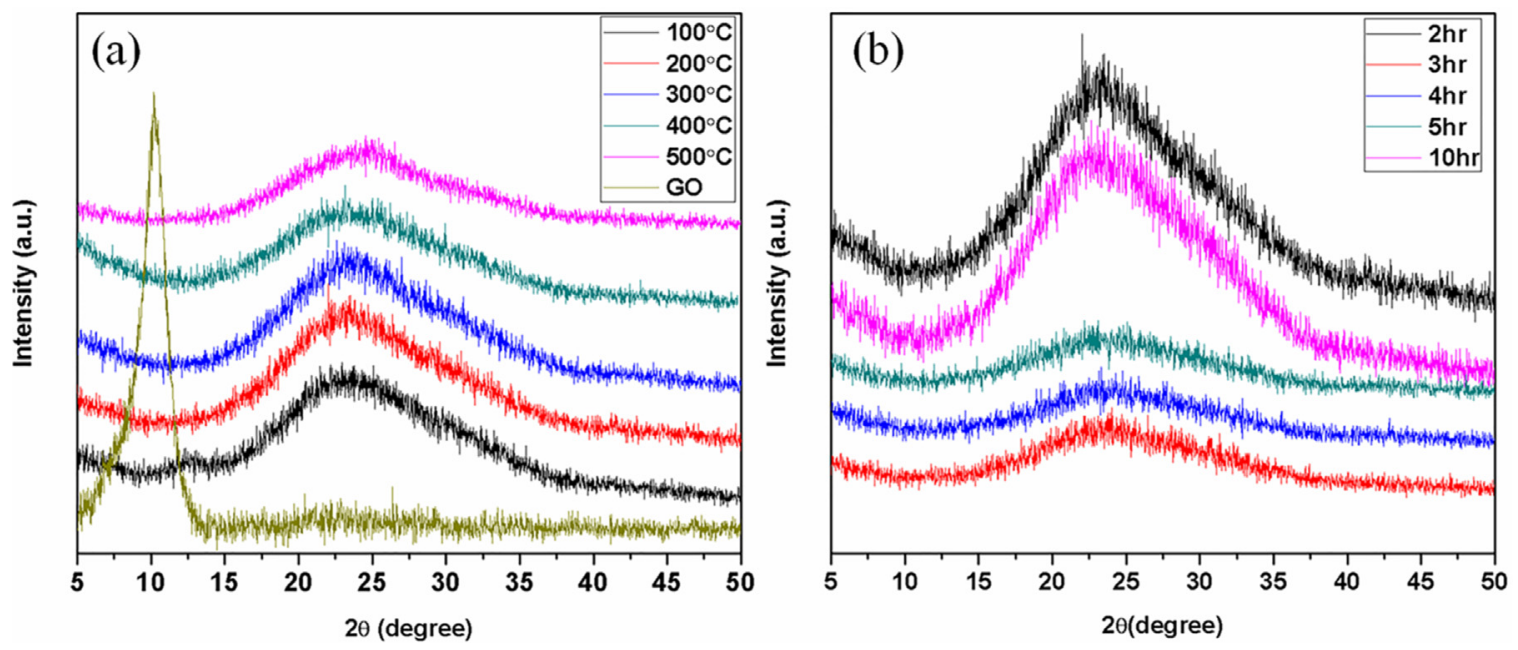

Fig. 1. XRD patterns of GO and rGO at different (a) reduction temperatures and (b) treatment time (at $200^{\circ} \mathrm{C}$ ).

from the interlayer spacing of the graphene layers. No GO peak was found for samples reduced at $200-500^{\circ} \mathrm{C}$, indicating reduction of $\mathrm{GO}$ to $\mathrm{rGO}$. At $100^{\circ} \mathrm{C}$, a small peak was observed at $12.72^{\circ}$ pointing to the presence of GO along with rGO. Thus, it may be concluded that significant reduction of GO starts at around $200{ }^{\circ} \mathrm{C}$, in $\mathrm{Ar}+\mathrm{H}_{2}$ atmosphere. In order to understand the effect of treatment time, XRD patterns were taken for varying treatment time, at $200^{\circ} \mathrm{C}$, (Fig. 1(b)). All XRD peaks of rGO were found between $24.06^{\circ}-24.49^{\circ}$ with d-spacing $3.63 \AA$-3.69 $\AA$. Absence of GO peak in all these XRD patterns indicates reduction of GO into $\mathrm{rGO}$, even for the shortest treatment time.

Fig. 2(a) shows the TEM image of GO at room temperature, which appears to be multilayered GO with lots of wrinkles. After reduction (at $200^{\circ} \mathrm{C}$ for $2 \mathrm{~h}$ ), wrinkles were found to be removed in rGO (Fig. 2(b)). TEM image of rGO showed good transparency which indicated the presence of few layered of rGO. Fig. 2(b) inset shows higher magnification TEM image of rGO reduced at $200^{\circ} \mathrm{C}$ for $2 \mathrm{~h}$. Selective area electron diffraction (SAED) pattern of the rGO (Fig. 2(d)) showed presence of planes matched with (002) and (004); which closely corresponded to $\mathrm{sp}^{2}$ hybridized hexagonal crystal lattice of graphitic plane. However, SAED pattern of GO (Fig. 2(c)) revealed polycrystalline structure.

For any film to be sustainable for practical applications, it is important to have good bonding between the film and the substrate. In order to understand the bonding between the rGO layer and the glass substrate, delamination energy was quantified by nanoscratch technique. This method was proven to be successful in quantifying delamination energy for a myriad of materials, including carbon nanotube [10], graphene [9,15], biological cells [8], thermally sprayed coatings [16] etc. In this technique, a fine Berkovich diamond tip of radius $\sim 100 \mathrm{~nm}$ was used to make $20 \mu \mathrm{m}$ long scratches along transverse direction of the substrate with velocity $0.5 \mu \mathrm{m} / \mathrm{s}$ and $10 \mu \mathrm{N}$ normal force (Fig. 3(a)). Due to the peeling-off of rGO film from the glass substrate, a change in lateral force was found. This change in lateral force with respect to lateral displacement gives the total energy to peel-off or delaminate the film from the substrate $[9,10,16-18]$. In order to generate a much better idea of the delamination energy, $\mathrm{C}-\mathrm{C}$ bond energy was deducted from the calculated total energy and the interlayer bond energy was neglected [9]. Fig. 4 shows the variation in delamination energy of rGO on soda lime glass with temperature and treatment time of reduction. Delamination energy of rGO shows inverse trend with temperature and treatment time, i.e. delamination energy decreases with increase in temperature (or treatment time). This inverse behavior can be related to the removal of highly electroneg- ative oxygen functional groups such as hydroxyl (attached to the interior aromatic domain of graphene sheet) and carboxyl group, which makes bond with dangling bonds present on the surface of substrate. These functional groups play important role in controlling the binding energy between the film and the substrate [3]. Removal of these functional groups between the interface of film and substrate creates lattice defect in the plane. Furthermore, it removes of some carbon atoms, which leads to poor adhesion between the rGO film and glass substrate.

Delamination of rGO layers by the nanoindentor is clearly observed from the FESEM image, as shown in Fig. 3(b). This figure also shows that the lateral force of indenter tip is sufficient to de-bond the rGO layers completely by tearing it off from the substrate.

rGO-on-soda lime glass is projected as a promising alternative for indium tin oxide (ITO) coated glass for TCE applications [12]. However, bonding between rGO layers and the glass substrate is expected to control properties of the TCEs. Sheet resistance of rGO films on glass substrate showed a decreasing trend with respect to reduction temperature (Fig. 4(a)). In the reduction of graphene oxide, the main influencing factors for conductivity of rGO are presence (or, absence) of functional groups attached between consecutive planes and to the edge. Functional groups (epoxy and hydroxyl) attached to the plane was reported to have more influence on conductivity than the groups attached to the edge (carboxyl, carbonyl and ester); since the conductivity of single layer graphene mainly depends on carrier transport within the carbon plane [3]. As reduction temperature increased, more number of functional groups were eliminated from the plane and the edge of the film. This led to a decrease in inter-planar distance (confirmed by XRD) resulting a rapid fall in sheet resistance, as observed between the temperature $200-300^{\circ} \mathrm{C}$. In this temperature range $\left(200-300^{\circ} \mathrm{C}\right)$, maximum number of functional groups were removed. In the range of $300-500^{\circ} \mathrm{C}$, probably less number of functional groups were removed, due to which a small variation in sheet resistance appeared between $300-400^{\circ} \mathrm{C}$ and almost linear behavior was seen in the range of $400-500^{\circ} \mathrm{C}$. Decay behavior was observed for the sheet resistance of rGO films on soda lime glass with respect to varying treatment time at $200^{\circ} \mathrm{C}$ (Fig. 4(b)). Low value of sheet resistance at $3 \mathrm{~h}$ indicates removal of more number of functional groups from the film. Overall, optimum values of $\mathrm{R}_{S}$ were found with a treatment temperature of $500^{\circ} \mathrm{C}$ and time $3 \mathrm{~h}$, which will be beneficial for TCE application. It may be recalled here (from Fig. 4) that such reduction parameters would lead to less delamination energy for the rGO film, which could have bad impact 


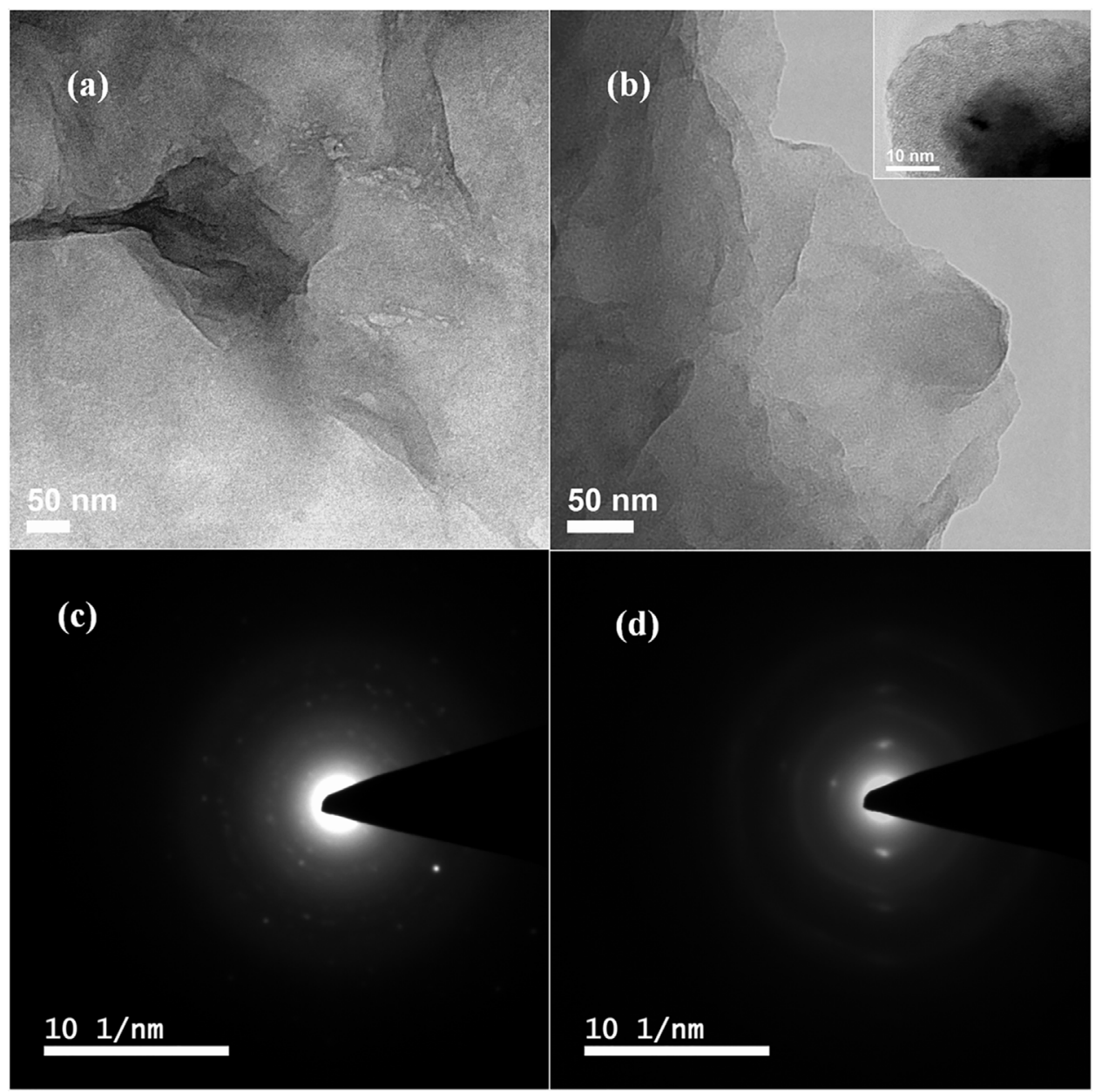

Fig. 2. TEM images and SAED patterns of GO [(a), (c)] and $\mathrm{rGO}[(\mathrm{b}),(\mathrm{d})]$ (reduced at $200^{\circ} \mathrm{C}$ for $2 \mathrm{~h}$ ). Inset of figure (b) is high magnification TEM image of the same rGO sample.
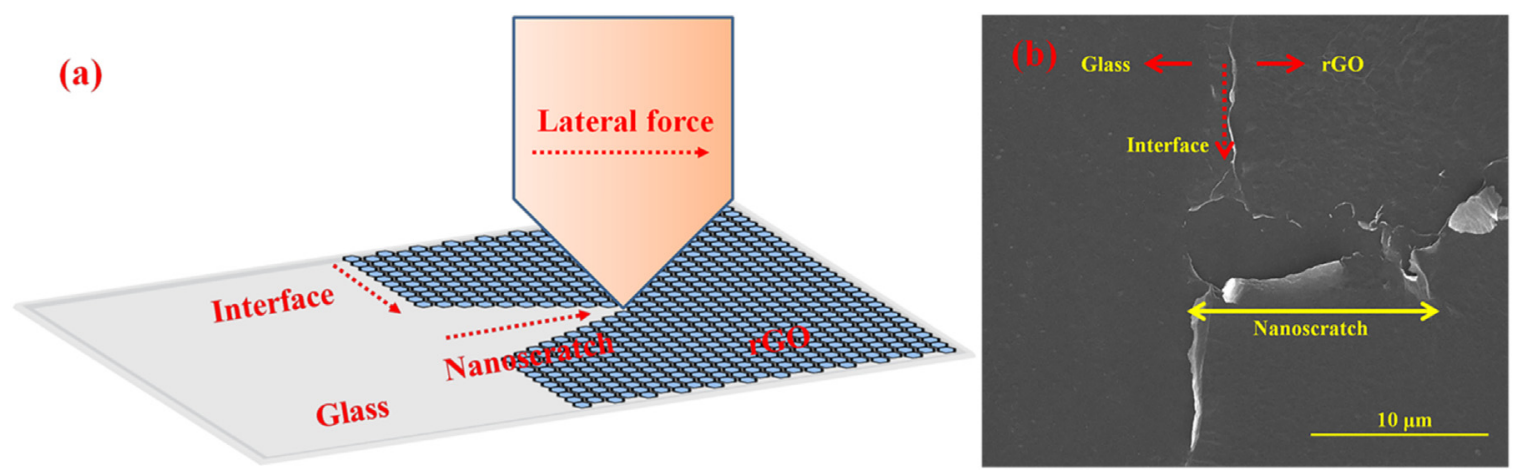

Fig. 3. (a) Schematic representation of nanoscratch study at $\mathrm{rGO}$ /glass interface (b) FESEM image of nanoscratched thermally reduced graphene oxide on soda lime glass at $200^{\circ} \mathrm{C}$ for $2 \mathrm{~h}$.

on the stability and life time of such TCEs. Hence, it is important to optimize the process parameters with respect to the properties of the TCEs. Optical transmittance is another significant property for TCEs, which also needs to be considered.

Fig. 5 shows the variation in transmittance of rGO films reduced at different temperature and treatment time. Decay in the transmittance of the films with varying temperature (Fig. 5) could be related to the thermal improvement of $\mathrm{sp}^{2}$ domains, which was confirmed by XPS (Fig. 6) [19]. Reduction in the peaks corresponding to $\mathrm{C}-\mathrm{O} / \mathrm{C}-\mathrm{OH}, \mathrm{C}=\mathrm{O}$ and $\mathrm{O}-\mathrm{C}=\mathrm{O}$ species indicated the thermal reduction of $\mathrm{GO}$ and improved $\mathrm{sp}^{2}$ domains in the $\mathrm{rGO}$ film. Studies had shown that $\mathrm{sp}^{2}$ domains were well recovered through thermal annealing of GO [20]. In a previous study, the authors had shown formation of more $\mathrm{sp}^{2}$ clusters during thermal annealing [12]. Also, thermal reduction led to removal of some carbon atom (through $\mathrm{CO}_{2}$ ) leaving behind structural defect with $\mathrm{C}-\mathrm{C}$ broken bond, which increased the scattering of light resulting in low transmittance with temperature $[3,21,22]$. Decreasing trend in the transmittance of the films was also found for samples reduced at $200^{\circ} \mathrm{C}$ with varying treatment time.

C1s core level spectral envelopes of GO and heat-treated GO (at $200^{\circ} \mathrm{C}$ ) samples were broad and asymmetrical indicating the 

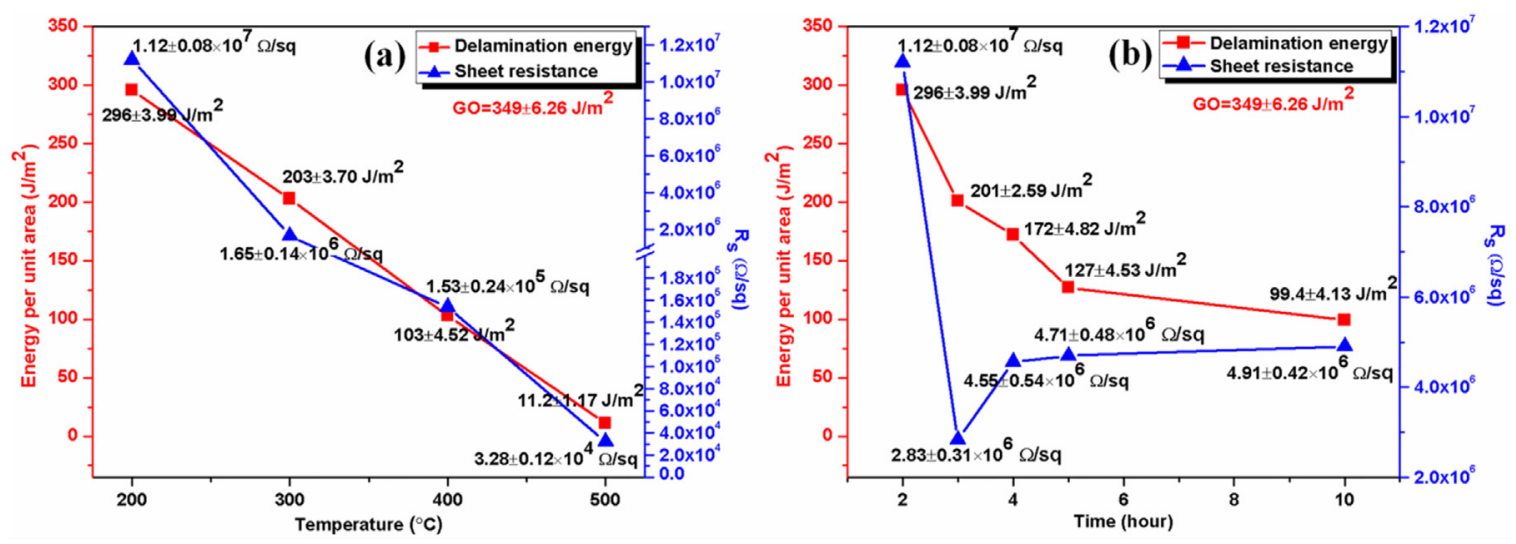

Fig. 4. Delamination energy and sheet resistance of $\mathrm{rGO}$ on soda lime glass at different (a) temperature and (b) treatment time (at $200{ }^{\circ} \mathrm{C}$ ).

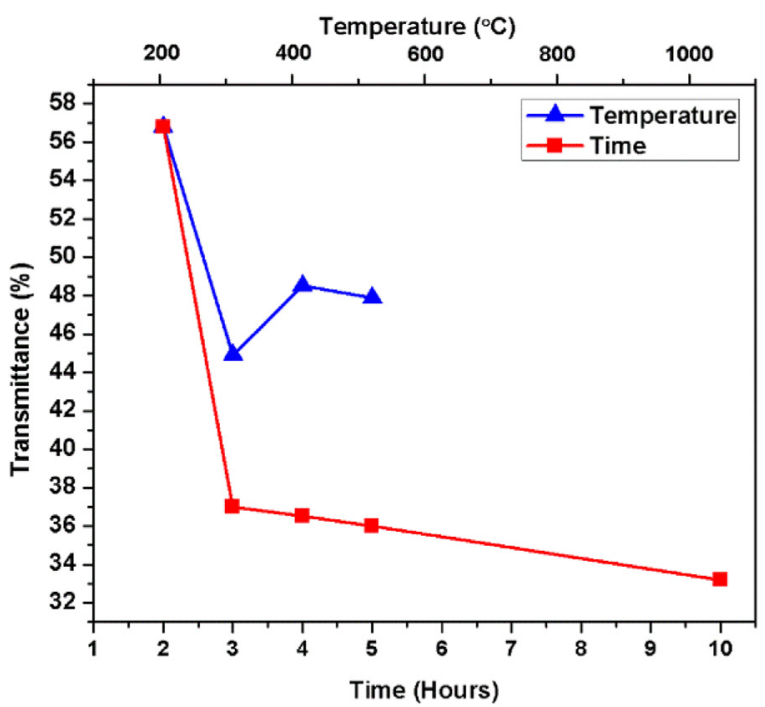

Fig. 5. Variation in transparency of rGO films with varying (a) temperature and (b) treatment time.

presence of several carbon components in the samples. Accordingly, spectra were curve-fitted into different component peaks and displayed in Fig. 6. Peaks at 284.5, 286.3, 287.8, 289.7 eV observed in the samples were related to $\mathrm{C}=\mathrm{C}, \mathrm{C}-\mathrm{O}$ or $\mathrm{C}-\mathrm{OH}, \mathrm{C}=\mathrm{O}$ and $\mathrm{O}-\mathrm{C}=\mathrm{O}$, respectively. Peak at $291.3 \mathrm{eV}$ was associated with the characteristic satellite of $\pi-\pi^{*}$ transition observed in these types of materials. The peak assignments agree well with the previous reported research work for this kind of materials [23-26]. It was observed that nature of spectra changed with heat-treatment temperature. With increase in temperature, intensity of the peak associated with $\mathrm{C}-\mathrm{O} / \mathrm{C}-\mathrm{OH}, \mathrm{C}=\mathrm{O}$ and $\mathrm{O}-\mathrm{C}=\mathrm{O}$ species decreased which resulted in increase in $\mathrm{C}: \mathrm{O}$ ratio from 2.5 (GO at room temperature) to $3.95\left(\mathrm{GO}\right.$ at $200^{\circ} \mathrm{C}$ ).

Delamination energy of the film should be high for a better life of the device. At $200{ }^{\circ} \mathrm{C}$, delamination energy of rGO was found to be high as compared to $300-500^{\circ} \mathrm{C}$. So the effect of treatment time on delamination energy, transparency and sheet resistance was further observed at $200^{\circ} \mathrm{C}$. In order to predict application of rGO-on-glass as transparent and conductive electrode, it is important to optimize properties for delamination, optical and electrical behavior at suitable processing conditions. Delamination and optical behavior were found to be better at lower temperature and shorter treatment time; while at higher temperature and more treatment-time, conductivity of the film was higher. Keeping in view of all the required properties, low reduction temperature and short treatment time appears to be the best suitable parameter. However, it may be noted here that the processing parameters can be optimized in a different way, according to the need of the applications.

\section{Conclusions}

Delamination energy of rGO on soda lime glass as a function of reduction temperature and treatment time was quantified by nanoscratch technique. An inverse behavior was found in delamination energy with respect to temperature-time due to the removal of oxygen functional groups from within the planes and the edges. Reduction of graphene oxide was found to be initiated at $200^{\circ} \mathrm{C}$, as confirmed by XRD and TEM. A continuous decay was observed in sheet resistance of the films with increasing reduction temperature and treatment time. This behavior could also be related to the elimination of functional groups during thermal reduction, which otherwise would have restricted the movement of electron during
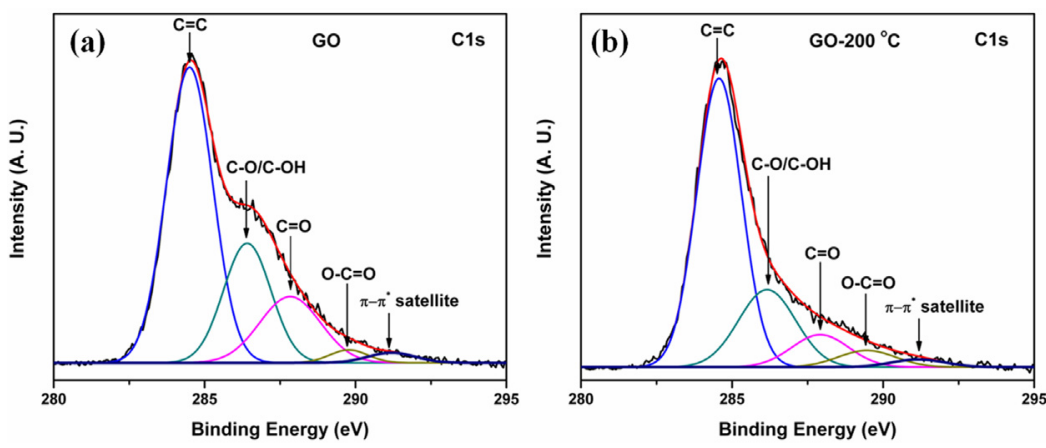

Fig. 6. C1s core level spectra of GO at (a) room temperature and (b) $200{ }^{\circ} \mathrm{C}$. 
conduction. Influence of functional groups was clearly observed on delamination energy, sheet resistance as well as in transmittance also. Thermal reduction of GO improved $\mathrm{sp}^{2}$ domains structure with structural defect and $\mathrm{C}-\mathrm{C}$ broken bonds in the rGO film, which resulted in the loss of transmittance of the films with respect to temperature and treatment time. Outcomes of the present study are anticipated to function as a pointer towards application of rGOon-soda lime glass as TCEs in opto-electronic devices, keeping in view of the structural stability and hence, a better life expectancy of the device.

\section{Acknowledgements}

RK and IL would like to thank Dr. Anirban Mitra, High Power Laser Laboratory, Department of Physics, IIT Roorkee for providing access to two point probe setup for sheet resistance measurement and Dr. Kantesh Balani, Department of Materials Science and Engineering, IIT Kanpur for TEM. This work was partially funded by the Faculty Initiation Grant (FIG-100612) of IL.

\section{References}

[1] X. Huang, Z. Yin, S. Wu, X. Qi, Q. He, Q. Zhang, Q. Yan, F. Boey, H. Zhang, Graphene-based materials: synthesis, characterization, properties, and applications, Small 7 (2011) 1876-1902.

[2] T.G. Deepak, G.S. Anjusree, T.A. Arun, S.V. Nair, A.S. Nair, A review on counter electrode materials in dye-sensitized solar cells, J. Mater. Chem. A 2 (2014) 4474-4490.

[3] S. Pei, H.-M. Cheng, The reduction of graphene oxide, Carbon 50 (2012) $3210-3228$

[4] H.A. Becerril, J. Mao, Z. Liu, R.M. Stoltenberg, Z. Bao, Y. Chen, Evaluation of solution-processed reduced graphene oxide films as transparent conductors, ACS Nano 2 (2008) 463-470.

[5] X. Wang, L. Zhi, K. Mullen, Transparent, conductive graphene electrodes for dye-sensitized solar cells, Nano Lett. 8 (2008) 323-327.

[6] X. Li, H. Wang, J.T. Robinson, H. Sanchez, G. Diankov, H. Dai, Simultaneous nitrogen doping and reduction of graphene oxide, J. Am. Chem. Soc. 131 (2009) 15939-15944.

[7] T. Yoon, W.C. Shin, T.Y. Kim, J.H. Mun, T.-S. Kim, B.J. Cho, Direct measurement of adhesion energy of monolayer graphene as-grown on copper and its application to renewable transfer process, Nano Lett. 12 (2012) 1448-1452.

[8] D. Lahiri, A.P. Benaduce, L. Kos, A. Agarwal, Quantification of carbon nanotube induced adhesion of osteoblast on hydroxyapatite using nano-scratch technique, Nanotechnology 22 (2011) 355703.

[9] S. Das, D. Lahiri, D.-Y. Lee, A. Agarwal, W. Choi, Measurements of the adhesion energy of graphene to metallic substrates, Carbon 9 (2013) 121-129.
[10] I. Lahiri, D. Lahiri, S. Jin, A. Agarwal, W. Choi, Carbon nanotubes: how strong is their bond with the substrate? ACS Nano 5 (2011) 780-787.

[11] D.W. Zhang, X.D. Li, H.B. Li, S. Chen, Z. Sun, X.J. Yin, S.M. Huang, Graphene-based counter electrode for dye-sensitized solar cells, Carbon 49 (2011) 5382-5388.

[12] R. Kumar, R.M. Kumar, D. Lahiri, I. Lahiri, Thermally reduced graphene oxide film on soda lime glass as transparent conducting electrode, Surf. Coat. Technol. 309 (2017) 931-937.

[13] D.C. Marcano, D.V. Kosynkin, J.M. Berlin, A. Sinitskii, Z. Sun, A. Slesarev, L.B. Alemany, W. Lu, J.M. Tour, Improved synthesis of graphene oxide, ACS Nano 4 (2010) 4806-4814.

[14] N.M. Huang, H.N. Lim, C.H. Chia, M.A. Yarmo, M.R. Muhamad, Simple room-temperature preparation of high-yield large-area graphene oxide, Int. J. Nanomed. 6 (2011) 3443-3448.

[15] S. Das, D. Lahiri, A. Agarwal, W. Choi, Interfacial bonding characteristics between graphene and dielectric substrates, Nanotechnology 25 (2014) 045707.

[16] A.K. Keshri, D. Lahiri, A. Agarwal, Carbon nanotubes improve the adhesion strength of a ceramic splat to the steel substrate, Carbon 49 (2011) 4340-4347.

[17] D. Lahiri, A.P. Benaduce, L. Kos, A. Agarwal, Quantification of carbon nanotube induced adhesion of osteoblast on hydroxyapatite using nano-scratch technique, Nanotechnology 22 (2011).

[18] K. Saini, R.M. Kumar, D. Lahiri, I. Lahiri, Quantifying bonding strength of CuO nanotubes with substrate using the nano-scratch technique, Nanotechnology 26 (2015) 305701

[19] J. Geng, H.-T. Jung, Porphyrin functionalized graphene sheets in aqueous suspensions: from the preparation of graphene sheets to highly conductive graphene films, J. Phys. Chem. C 114 (2010) 8227-8234.

[20] G. Eda, G. Fanchini, M. Chhowalla, Large-area ultrathin films of reduced graphene oxide as a transparent and flexible electronic material, Nat. Nanotechnol. 3 (2008) 270-274.

[21] H.C. Schniepp, J.L. Li, M.J. McAllister, H. Sai, M. Herrera-Alonso, D.H. Adamson, R.K. Prud'homme, R. Car, D.A. Saville, I.A. Aksay, Functionalized single graphene sheets derived from splitting graphite oxide, J. Phys. Chem. B 110 (2006) 8535-8539.

[22] K.N. Kudin, B. Ozbas, H.C. Schniepp, R.K. Prud'homme, I.A. Aksay, R. Car, Raman spectra of graphite oxide and functionalized graphene sheets, Nano Lett. 8 (2007) 36-41.

[23] X. Song, Y. Yang, J. Liu, H. Zhao, PS colloidal particles stabilized by graphene oxide, Langmuir 27 (2011) 1186-1191.

[24] C. Mattevi, G. Eda, S. Agnoli, S. Miller, K.A. Mkhoyan, O. Celik, D. Mastrogiovanni, G. Granozzi, E. Garfunkel, M. Chhowalla, Evolution of electrical chemical, and structural properties of transparent and conducting chemically derived graphene thin films, Adv. Funct. Mater. 19 (2009) 2577-2583.

[25] W. Zhang, A. Tanaka, K. Wazumi, Y. Koga, Structural, mechanical and tribological properties of diamond-like carbon films prepared under different substrate bias voltage, Diamond Relat. Mater. 11 (2002) 1837-1844.

[26] S. Santra, P.K. Hota, R. Bhattacharyya, P. Bera, P. Ghosh, S.K. Mandal, Palladium nanoparticles on graphite oxide: a recyclable catalyst for the synthesis of biaryl cores, ACS Catal. 3 (2013) 2776-2789. 